\title{
Deficiency of Dystrophin-associated Proteins in Duchenne Muscular Dystrophy Patients Lacking COOH-terminal Domains of Dystrophin
}

\author{
Kiichiro Matsumura, " Fernando M. S. Tomé," Victor lonasescu," James M. Ervasti, * Richard D. Anderson, * \\ Norma B. Romero, "\#l Dominique Simon," Dominique Récan, " Jean-Claude Kaplan,' Michel Fardeau," \\ and Kevin P. Campbell* \\ ${ }^{*}$ Howard Hughes Medical Institute and Department of Physiology and Biophysics, University of Iowa College of Medicine, Iowa City, \\ Iowa 52242; ${ }^{\ddagger}$ Institut National de la Santé et de la Recherche Médicale (INSERM) U153, 75005 Paris, France; ${ }^{8}$ Department of \\ Pediatrics, University of Iowa College of Medicine, Iowa City, Iowa 52242; "Laboratoire de Pathologie Musculaire, Hôpital Robert \\ Debré, 75019 Paris, France; and 'INSERM U129, Institut Cochin de Génétique Moléculaire, 75014 Paris, France
}

\begin{abstract}
Dystrophin, the protein product of the Duchenne muscular dystrophy (DMD) gene, is a cytoskeletal protein tightly associated with a large oligomeric complex of sarcolemmal glycoproteins including dystroglycan, which provides a linkage to the extracellular matrix component, laminin. In DMD, the absence of dystrophin leads to a drastic reduction in all of the dystrophin-associated proteins, causing the disruption of the linkage between the subsarcolemmal cytoskeleton and the extracellular matrix which, in turn, may render muscle cells susceptible to necrosis. The $\mathrm{COOH}$-terminal domains (cysteinerich and carboxyl-terminal) of dystrophin have been suggested to interact with the sarcolemmal glycoprotein complex. However, truncated dystrophin lacking these domains was reported to be localized to the sarcolemma in four DMD patients recently. Here we report that all of the dystrophin-associated proteins are drastically reduced in the sarcolemma of three DMD patients in whom dystrophin lacking the $\mathrm{COOH}$-terminal domains was properly localized to the sarcolemma. Our results indicate that the $\mathrm{COOH}$-terminal domains of dystrophin are required for the proper interaction of dystrophin with the dystrophin-associated proteins and also support our hypothesis that the loss of the dystrophin-associated proteins in the sarcolemma leads to severe muscular dystrophy even when truncated dystrophin is present in the subsarcolemmal cytoskeleton. (J. Clin. Invest. 1993. 92:866-871.) Key words: Duchenne muscular dystrophy • dystrophin • dystrophin-glycoprotein complex • dystrophin-associated proteins • dystroglycan
\end{abstract}

\section{Introduction}

Duchenne muscular dystrophy (DMD) ${ }^{1}$ is caused by the absence of dystrophin, a large membrane cytoskeletal protein ( 1 ,

Address correspondence to Dr. Kevin P. Campbell, Howard Hughes Medical Institute, University of Iowa College of Medicine, 400 EMRB, Iowa City, IA 52242.

Received for publication 24 November 1992 and in revised form 17 February 1993.

1. Abbreviations used in this paper: BMD, Becker muscular dystrophy; DMD, Duchenne muscular dystrophy; 35DAG, 35-kD dystrophin-associated glycoprotein; 43DAG, 43-kD dystroglycan; 50DAG, 50-kD dystrophin-associated glycoprotein; DRP, dystrophin-related protein; 156DAG, 156-kD dystroglycan; 59DAP, 59-kD dystrophin-associated protein; SCARMD, severe childhood autosomal recessive muscular dystrophy.

J. Clin. Invest.

(c) The American Society for Clinical Investigation, Inc.

$0021-9738 / 93 / 08 / 0866 / 06 \quad \$ 2.00$

Volume 92, August 1993, 866-871
2). Dystrophin is associated with a large oligomeric complex of sarcolemmal glycoproteins, including dystroglycan, which binds the extracellular matrix component, laminin (3-10). Dystrophin also interacts with $\mathrm{F}$-actin $(11,12)$. These findings indicate that the dystrophin-glycoprotein complex spans the sarcolemma to provide a linkage between the subsarcolemmal cytoskeleton and the extracellular matrix. In DMD, the absence of dystrophin leads to a great reduction in all of the dystrophin-associated proteins, causing the disruption of the linkage between the subsarcolemmal cytoskeleton and the extracellular matrix. This disruption of the linkage may, in turn, render muscle cells susceptible to necrosis $(4,10,13-15)$. The same sarcolemmal defect also exists in a mosaic of dystrophin-deficient muscle fibers in asymptomatic DMD carrier and is presumed to be responsible for the muscle fiber degeneration in this condition (16). The significant role of the loss of the dystrophin-associated proteins in the molecular pathogenesis of DMD is supported by our recent findings that the specific deficiency of the $50-\mathrm{kD}$ dystrophin-associated glycoprotein (50DAG) alone causes severe childhood autosomal recessive muscular dystrophy with DMD-like phenotype (SCARMD) (15).

In our proposed model of the dystrophin-glycoprotein complex, dystrophin is presumed to be localized to the subsarcolemmal region due to its dual interaction with the glycoprotein complex in the sarcolemma and the subsarcolemmal F-actin cytoskeleton (9). Recently the $\mathrm{NH}_{2}$-terminal domain of dystrophin was expressed as a fusion protein and shown to interact with F-actin $(11,12)$. The exact domain of dystrophin which interacts with the dystrophin-associated proteins remains unknown. However, the $\mathrm{COOH}$-terminal domains (cysteine-rich and carboxyl-terminal) of dystrophin have been suggested to be involved in the interaction with the dystrophin-associated proteins because of the following observations (9):(a) the lack of significant homology between the carboxyl-terminal domain of dystrophin and proteins of known function except for dystrophin-related protein (DRP), an autosomal homologue of dystrophin $(2,17),(b)$ the conservation of the cysteine-rich and carboxyl-terminal domains among different species $(18),(c)$ the clinical observation that the phenotype of the patients with deletions in the cysteine-rich and carboxyl-terminal domains is severe (19), and $(d)$ the results of immunogold labeling studies $(20,21)$. The results of limited calpain digestion of the purified dystrophin-glycoprotein complex and the demonstration of the association of DRP with the dystrophin-associated proteins in $\mathrm{mdx}$ muscle are consistent with this hypothesis (22-24).

Recently, truncated dystrophin lacking the $\mathrm{COOH}$-terminal domains was reported to be properly localized to the sarcolemma in four unique patients with DMD, leading to an alter- 
native hypothesis that another domain in dystrophin may interact with the sarcolemmal glycoprotein complex (25-29). A modified model of the dystrophin-glycoprotein complex was proposed (26) and the $\mathrm{NH}_{2}$-terminal domain of dystrophin was hypothesized to interact with the dystrophin-associated proteins $(26,28)$. However, the possibility that truncated dystrophin with the intact $\mathrm{NH}_{2}$-terminal domain may be properly targeted to the sarcolemma by associating with other subsarcolemmal cytoskeletal component(s) even though it is not associated with the dystrophin-associated proteins in the sarcolemma was not addressed. Furthermore, the molecular mechanism underlying the severe phenotype of these patients in spite of the expression and proper localization of truncated dystrophin is unknown (25-29). To address these issues, we investigated the status of the dystrophin-associated proteins in the DMD patients lacking the $\mathrm{COOH}$-terminal domains of dystrophin.

\section{Methods}

\section{Case reports}

Patient 1 . This 18-mo-old patient was fully described elsewhere (26). Briefly, the patient suffers from a combination of muscular dystrophy, glycerol kinase deficiency, congenital adrenal hypoplasia, and poor psychomotor development (26). DNA analysis of the dystrophin gene revealed a large deletion removing the distal part of the gene beyond exon 49 which encodes the distal portion of the rod domain, the cysteine-rich domain, and the carboxyl-terminal domain, and extending beyond the glycerol kinase and congenital adrenal hypoplasia genes (26). A $270-\mathrm{kD}$ band was detected by the antibody against the $\mathrm{NH}_{2}$ terminus or central domain of dystrophin but was not detected by the antibody against the $\mathrm{COOH}$ terminus in the immunoblot analysis (26). The biopsy specimen investigated in the present study was obtained from the deltoid muscle at the age of $18 \mathrm{mo}$.

Patient 2. This 2-yr old boy has positive family history with one maternal uncle with DMD. He has a history of progressive weakness of his legs starting at $18 \mathrm{mo}$ of age. Neurological examination showed proximal weakness of the extremities, hypertrophy of the calves, and tightness of the heelcords. Serum creatine kinase level was elevated to 15,000 IU (normal 50-200 IU). Histology of the biopsied quadriceps muscle was consistent with severe myopathy. DNA analysis of the dystrophin gene was not performed.

Patient 3. This 4-yr old boy, the elder brother of patient 2, was developmentally delayed: he crawled at $18 \mathrm{mo}$, walked at $2 \mathrm{yr}$, said his first word at $3 \mathrm{yr}$, and was not toilet trained at $4 \mathrm{yr}$ of age. First signs of weakness manifested at the age of $3 \mathrm{yr}$. Neurological examination revealed proximal weakness of the extremities, positive Gowers sign, and hypertrophy of the calves. Serum creatine kinase level was elevated to $35,760 \mathrm{IU}$. Histology of the biopsied quadriceps muscle was consistent with severe myopathy. DNA analysis of the dystrophin gene was not performed.

\section{Antibodies}

Affinity-purified rabbit antibodies against the first 15 amino acids of the $\mathrm{NH}_{2}$ terminus and the last 10 amino acids of the $\mathrm{COOH}$ terminus of dystrophin were characterized previously $(6-8,13)$. A cDNA clone corresponding to repeat units 21 and 22 of the rod domain of human dystrophin (residues 2263 to 2557 ) was isolated from a rabbit skeletal muscle cDNA library, subcloned into pGEX vector (Pharmacia LKB Biotechnology, Piscataway, NJ) and expressed as a GST-fusion protein by IPTG induction $(2,10)$. Sheep antibody against this fusion protein was affinity purified as described $(13,14)$. Monoclonal antibody IVD3 ${ }_{1}$ against the 50-kD dystrophin-associated glycoprotein (50DAG) was characterized previously $(4,6)$. Specific antibodies against the 156-kD dystroglycan (156DAG), 59-kD dystrophin-associated protein (59DAP), 50DAG, 43-kD dystroglycan (43DAG), and 35-kD dystrophin-associated glycoprotein (35DAG) were affinity purified as described $(10,13-15)$.

\section{Immunohistochemistry}

Indirect immunofluorescence microscopy of $7-\mu \mathrm{m}$ thick cryosections from skeletal muscle biopsy specimens was performed as described previously $(6,13-15)$. Blocking was performed by a 30-min incubation with 5\% BSA in PBS ( $50 \mathrm{mM}$ sodium phosphate, $\mathrm{pH} \mathrm{7.4,0.9 \%}$ $\mathrm{NaCl}$ ). Incubation with primary antibodies was performed for $1 \mathrm{~h}$. In the case of rabbit or mouse primary antibodies, cryosections were incubated with 1:200 diluted fluorescein-labeled goat anti-rabbit IgG or anti-mouse IgG (Boehringer-Mannheim Corp., Indianapolis, IN) for 1 $h$. In the case of sheep primary antibodies, cryosections were incubated for $30 \mathrm{~min}$ with 1:500 diluted biotinylated rabbit anti-sheep IgG ( Vector Laboratories, Inc., Burlingame, CA) followed by incubation for 30 min with 1:1,000 diluted fluorescein-conjugated streptavidin (Jackson ImmunoResearch Laboratories, Inc., West Grove, PA). Incubation with all antibodies was performed at room temperature. Each incubation was followed by extensive washing with PBS. Final specimens were examined under a Zeiss Axioplan fluorescence microscope. For reliable comparison, cryosections from different patients were placed on the same microscopy slide and processed identically. In addition, photographs were taken under identical conditions with the same exposure time.

\section{Results and Discussion}

Antibodies against the $\mathrm{NH}_{2}$ terminus, rod domain, and $\mathrm{COOH}$ terminus of dystrophin and antibodies against the dystrophinassociated proteins all stained the sarcolemma in the skeletal muscle from normal humans as described previously $(4,10$, 14, 15), (Figs. 1 and 2). In the skeletal muscle from typical DMD patients, sarcolemma was not stained by the antibodies against the $\mathrm{NH}_{2}$ terminus, rod domain or $\mathrm{COOH}$ terminus of dystrophin, and the staining for all of the dystrophin-associated proteins was greatly reduced in the sarcolemma (Figs. 1 and 2) $(4,10,14,15,24)$.

In the skeletal muscle from the three DMD patients described in Case Reports, antibodies against the $\mathrm{NH}_{2}$ terminus and rod domain of dystrophin stained the sarcolemma but an antibody against the $\mathrm{COOH}$ terminus of dystrophin did not stain the sarcolemma (Figs. 1 and 2). The staining for all of the dystrophin-associated proteins was greatly reduced in the sarcolemma (Figs. 1 and 2). The staining pattern of the dystrophin-associated proteins was indistinguishable from that of typical DMD patients (Figs. 1 and 2).

Here we have investigated the status of all the components of the dystrophin-glycoprotein complex in three DMD patients with peculiar expression of dystrophin. Our patients included a patient reported previously (patient 1) (26). DNA analysis of the dystrophin gene in this patient indicates that truncated dystrophin in this patient lacks the distal portion of the rod domain and the entire cysteine-rich and carboxyl-terminal domains. Information about the defect of the dystrophin gene was not available for the other two patients (patients 2 and 3 ). However, the results of immunohistochemistry using antibodies against the three distinct domains of dystrophin indicate that the defect involves a portion of dystrophin distal to the 21 st and/or 22 nd repeat units of the rod domain in these two brothers.

Immunohistochemistry using antibodies against the three distinct domains of dystrophin demonstrated that dystrophin lacking the $\mathrm{COOH}$-terminal portions was expressed and properly localized to the sarcolemmal region in all three patients reported here. These results are identical to those reported pre- 


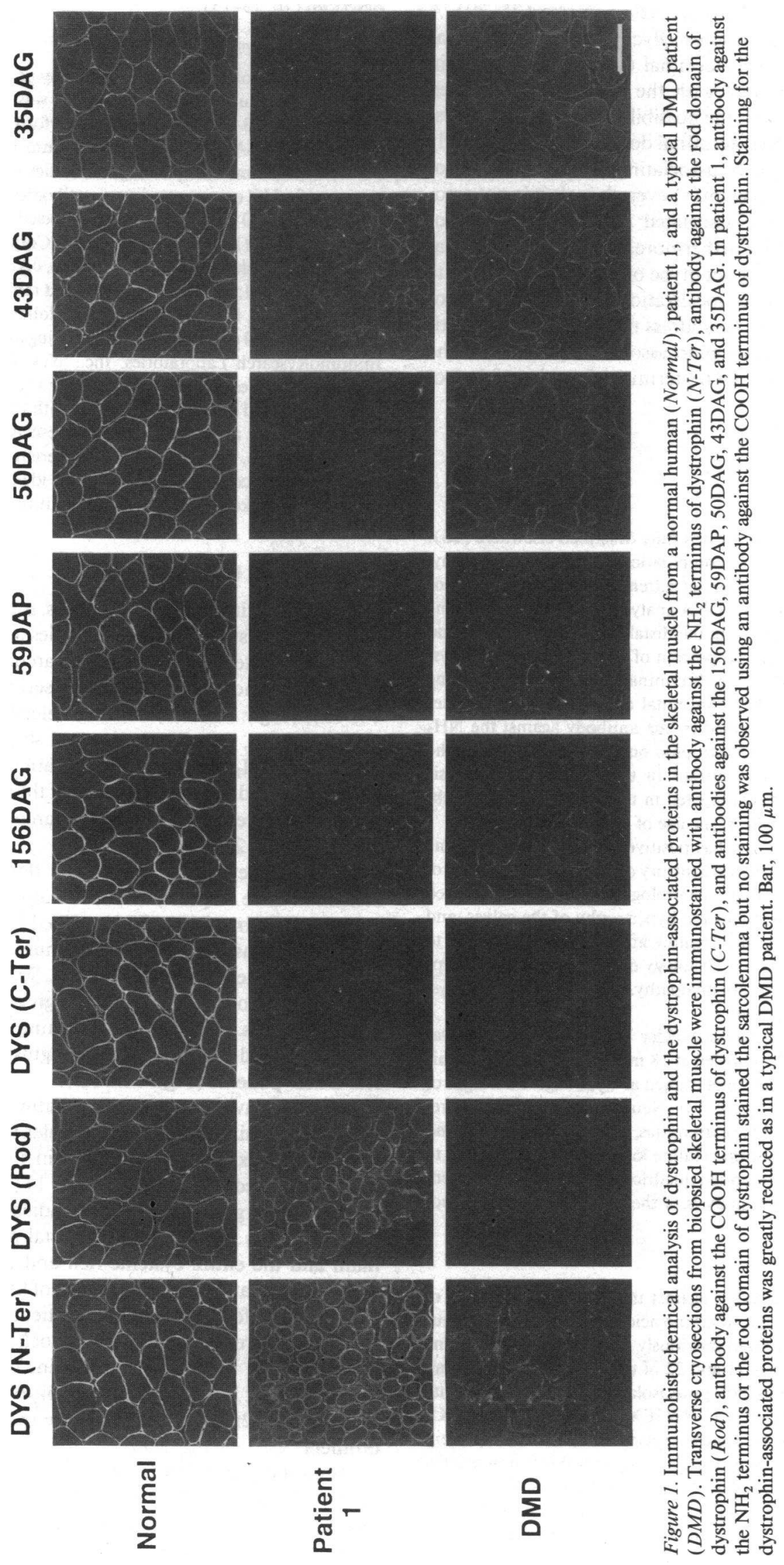



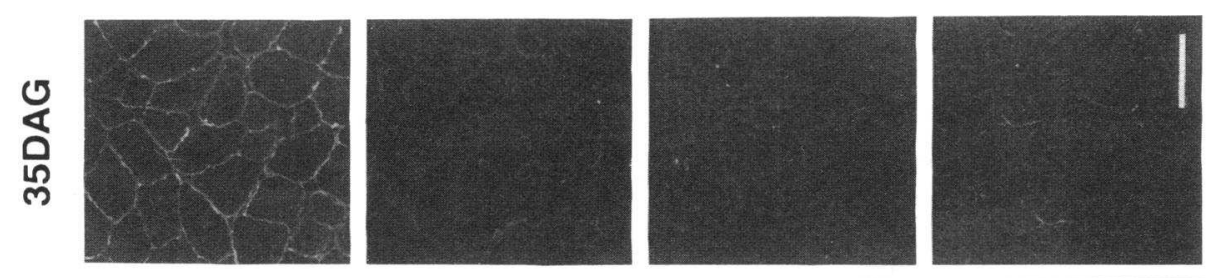

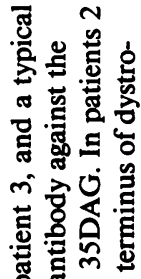
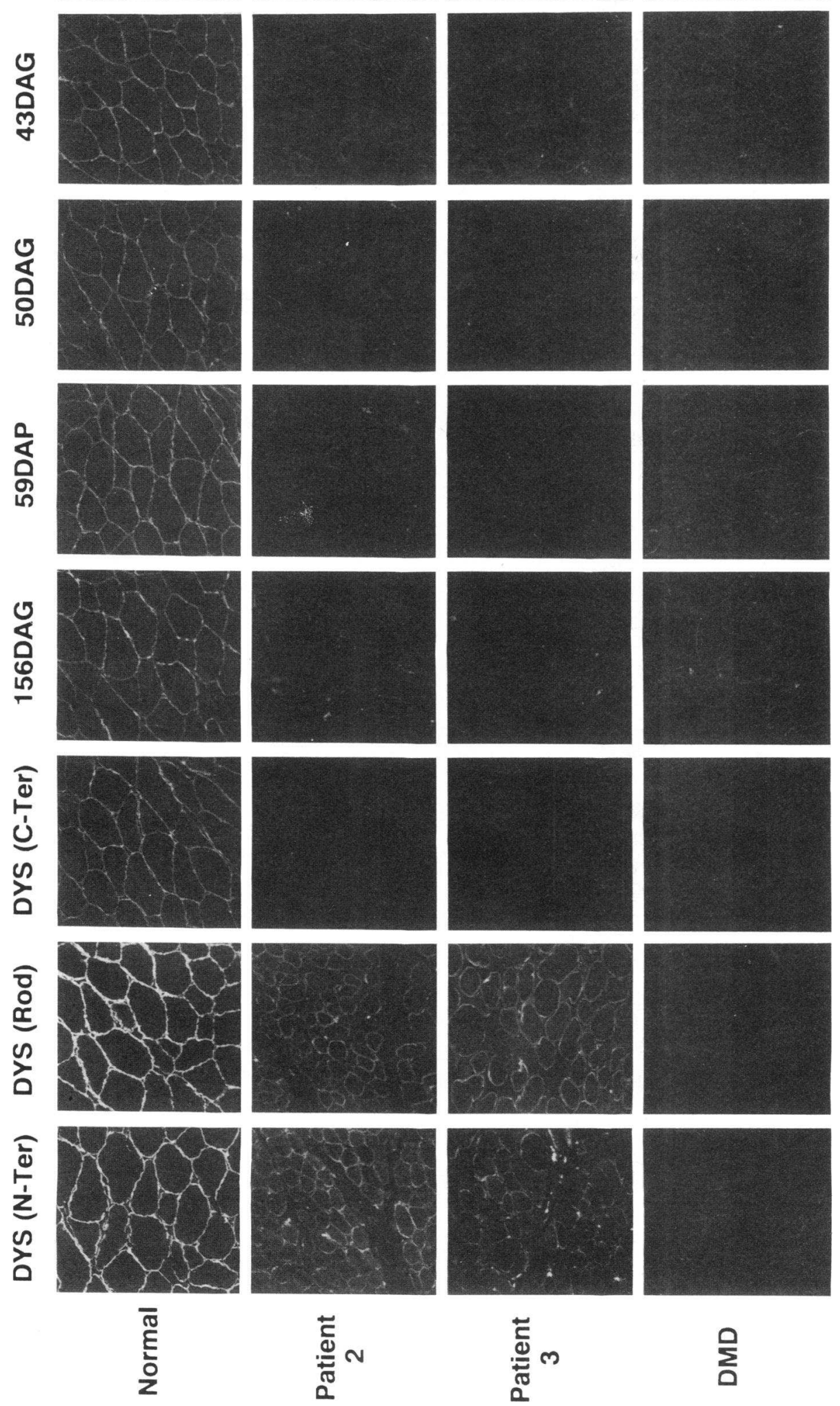

홓ํำ

范

要主

․ํำ

ธิ์ 之各合

웅 울

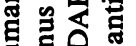

름ํำ

สำ

和乐象

乙然毒

๘

氞志兽

능

\%

ह 8

퐁 음 든

空的 . 垫

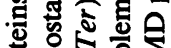

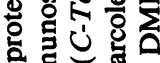

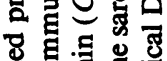
可起啳 응 政 \% s. 흘 응

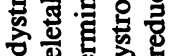
웡 要 贾 空 둥 영 흥

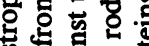
점 을

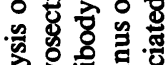

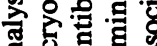
त ฮె 表运

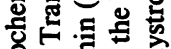
施 응 过 궁응

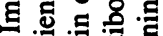
话光 ริ

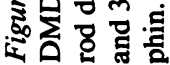


viously (25-29). However, the present study is the first to demonstrate the loss of all the dystrophin-associated proteins in the sarcolemma of these patients, a phenomenon characteristic of DMD sarcolemma. The loss in all of the dystrophin-associated proteins including the laminin-binding dystroglycan indicates that the linkage between the subsarcolemmal cytoskeleton and the extracellular matrix is disrupted in spite of the presence of truncated dystrophin in these patients. This is presumed to be the cause of severe muscular dystrophy. This hypothesis is also consistent with our observations that the dystrophin-associated proteins were fairly well preserved in the sarcolemma of the Becker muscular dystrophy (BMD) patients having in-frame deletions in the rod domain of dystrophin (repeat units 3-20) (30).

Our results suggest that the domain of dystrophin which interacts with the glycoprotein complex is missing in the three patients reported here and thus support the hypothesis that the $\mathrm{COOH}$-terminal portions of dystrophin are required for proper stabilization of the glycoprotein complex. This is consistent with the recent biochemical findings that the cysteine-rich domain and the first half of the carboxyl-terminal domain remained bound to the dystrophin-associated proteins after limited calpain digestion (22) and with the recent demonstration that DRP, which has the cysteine-rich and carboxyl-terminal domains highly homologous to those of dystrophin, is associated with the dystrophin-associated proteins in $\mathrm{mdx}$ muscle $(17,24)$.

In our proposed model of the dystrophin-glycoprotein complex, the 59DAP was hypothesized to be associated with the other dystrophin-associated proteins on the $\mathrm{COOH}$-terminal domains of dystrophin but the possibility that the 59DAP may be associated with the other domains of dystrophin, apart from the other dystrophin-associated proteins, was not excluded (9). Thus, the present result demonstrating the loss of the 59DAP in the DMD patients with truncated dystrophin suggests that the 59DAP interacts with the $\mathrm{COOH}$-terminal domains of dystrophin.

The mechanism by which dystrophin lacking the $\mathrm{COOH}$ terminal domains was properly localized to the sarcolemma in these patients is unclear. Presumably, truncated dystrophin with the intact $\mathrm{NH}_{2}$-terminal domain can interact properly with other subsarcolemmal cytoskeletal component(s). For instance, the actin-binding site in the $\mathrm{NH}_{2}$-terminal domain may associate with subsarcolemmal cytoskeletal proteins such as $\gamma$-actin which could target truncated dystrophin to the subsarcolemmal region.

The present study has significant implications not only for the differential diagnosis between DMD and BMD, but also for the elucidation of the molecular mechanism leading to muscle degeneration in these diseases. Our results suggest that the status of the dystrophin-associated proteins in the sarcolemma may be more directly correlated with the phenotype of the patients than the status of the expression of dystrophin itself. The recent finding that the specific deficiency of the 50DAG alone causes SCARMD also supports this hypothesis (15). The phenotype of DMD is presumed to be caused by the loss of the dystrophin-associated proteins in the sarcolemma which, in turn, can be due to either the complete absence of dystrophin or the specific absence or dysfunction of the domain of dystrophin which interacts with the dystrophin-associated proteins (Fig. 3). The former is the case in the typical DMD patients and the latter is the case in the DMD patients lacking the a

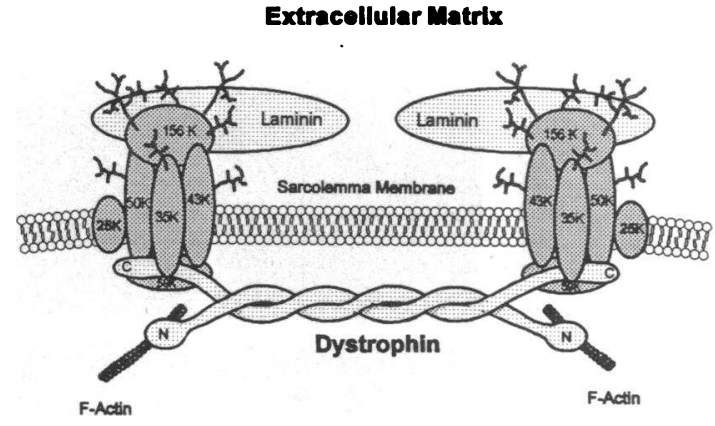

b

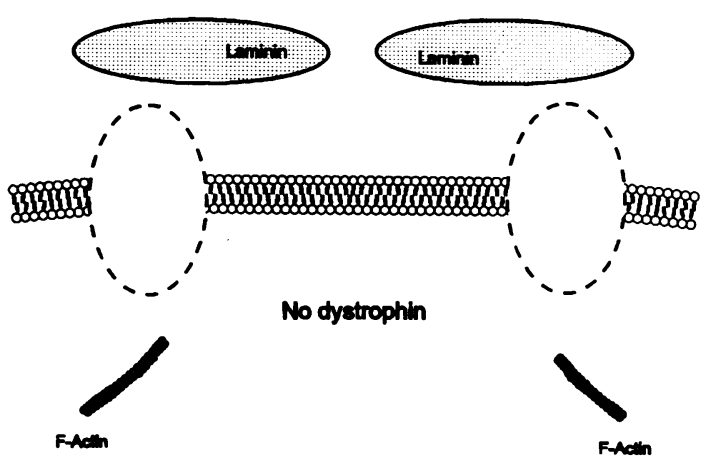

C

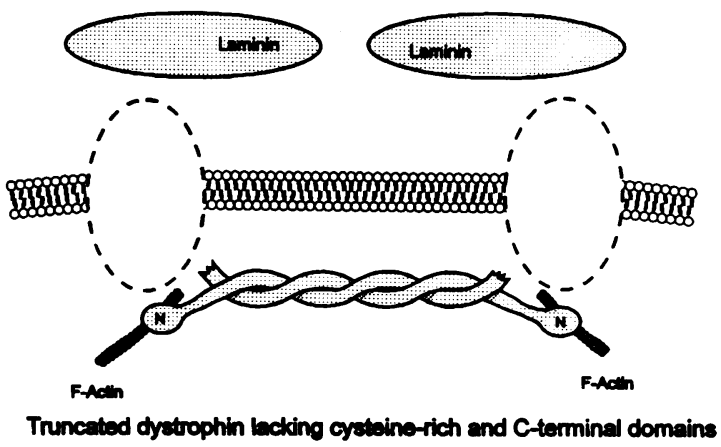

Figure 3. Schematic model of the dystrophin-glycoprotein complex in normal state $(a)$, DMD with complete absence of dystrophin $(b)$, and DMD lacking the $\mathrm{COOH}$-terminal domains of dystrophin.

COOH-terminal domains of dystrophin as in our patients. Our hypothesis is also consistent with the observation of Koenig et al. (19), who correlated the phenotype with dystrophin alterations at the genomic level and reported severe phenotype for the patients with deletions involving the exons which correspond to the cysteine-rich and the first half of the carboxyl-terminal domains. Indeed our findings provide a functional explanation for their observation.

Our hypothesis predicts that the in-frame mutations of the dystrophin gene having no effects on the domain which interacts with the glycoprotein complex will not result in the loss of the dystrophin-associated proteins and thus, lead to only a mild disease phenotype. One exception could be the mutations which affect the domain of dystrophin which interacts with $\mathrm{F}$-actin. Indeed mutations involving the $\mathrm{NH}_{2}$-terminal domain of dystrophin lead to a phenotype of severe $\operatorname{BMD}(19,31,32)$. 
Thus, it is important to investigate the status of the dystrophinassociated proteins in BMD patients having a variety of mutations to clarify the molecular mechanism leading to muscle degeneration in BMD.

Finally, our results indicate that caution is required in the interpretation of the immunohistochemical and immunoblot analyses of dystrophin in biopsied skeletal muscle from DMD/ BMD patients: analysis using only antibodies against dystrophin can be quite misleading as exemplified in the case of the DMD patients lacking the $\mathrm{COOH}$-terminal domains of dystrophin. Furthermore, we have shown that secondary loss of dystrophin due to the deficiency of the 50DAG can occur in the advanced stages of SCARMD, making the differential diagnosis between DMD, BMD, and SCARMD difficult by the immunochemical analysis of dystrophin alone (15). Thus, immunochemical analysis of the dystrophin-associated proteins, in addition to dystrophin, will help the accurate diagnosis of muscular dystrophies.

\section{Acknowledgments}

We would like to thank S. D. Kahl, C. J. Leveille, M. J. Mullinnix, and H. Collin for the expert technical assistance, and Dr. S. L. Roberds for helpful comments.

K. P. Campbell is an Investigator of the Howard Hughes Medical Institute. This work was also supported by the Muscular Dystrophy Association and the Association Française contre les Myopathies (France). J. M. Ervasti was the Carl M. Pearson Postdoctoral Fellow of the Muscular Dystrophy Association while contributing to this study.

\section{References}

1. Hoffman, E. P., R. H. Brown, and L. M. Kunkel. 1987. Dystrophin: the protein product of the Duchenne muscular dystrophy locus. Cell. 51:919-928.

2. Koenig, M., A. P. Monaco, and L. M. Kunkel. 1988. The complete sequence of dystrophin predicts a rod-shaped cytoskeletal protein. Cell. 53:219228.

3. Campbell, K. P., and S. D. Kahl. 1989. Association of dystrophin and an integral membrane glycoprotein. Nature (Lond.). 338:259-262.

4. Ervasti, J. M., K. Ohlendieck, S. D. Kahl, M. G. Gaver, and K. P. Campbell. 1990. Deficiency of a glycoprotein component of the dystrophin complex in dystrophic muscle. Nature (Lond.). 345:315-319.

5. Yoshida, M., and E. Ozawa. 1990. Glycoprotein complex anchoring dystrophin to sarcolemma. J. Biochem (Tokyo). 108:748-752.

6. Ohlendieck, K., J. M. Ervasti, J. B. Snook, and K. P. Campbell. 1991. Dystrophin-glycoprotein complex is highly enriched in isolated skeletal muscle sarcolemma. J. Cell Biol. 112:135-148.

7. Ervasti, J. M., S. D. Kahl, and K. P. Campbell. 1991. Purification of dystrophin from skeletal muscle. J. Biol. Chem. 266:9161-9165.

8. Ohlendieck, K., and K. P. Campbell. 1991. Dystrophin constitutes 5\% of membrane cytoskeleton in skeletal muscle. FEBS ( Fed. Eur. Biochem. Soc.) Lett. 283:230-234

9. Ervasti, J. M., and K. P. Campbell. 1991. Membrane organization of the dystrophin-glycoprotein complex. Cell. 66:1121-1131.

10. Ibraghimov-Beskrovnaya, O., J. M. Ervasti, C. J. Leveille, C. A. Slaughter, S. W. Sernett, and K. P. Campbell. 1992. Primary structure of dystrophin-associated glycoproteins linking dystrophin to the extracellular matrix. Nature (Lond.). 355:696-702.

11. Hemmings, L., P. A. Kuhlmann, and D. R. Critchley. 1992. Analysis of the actin-binding domain of $\alpha$-actinin by mutagenesis and demonstration that dystrophin contains a functionally homologous domain. J. Cell Biol. 116:13691380.
12. Way, M., B. Pope, R. A. Cross, J. Kendrick-Jones, and A. G. Weeds. 1992. Expression of the $\mathrm{N}$-terminal domain of dystrophin in $E$. coli and demonstration of binding to F-actin. FEBS (Fed. Eur. Biochem. Soc.) Lett. 301:243-245.

13. Ohlendieck, K., and K. P. Campbell. 1991. Dystrophin-associated proteins are greatly reduced in skeletal muscle from $\mathrm{mdx}$ mice. J. Cell Biol. 115:1685-1694.

14. Ohlendieck, K., K. Matsumura, V. V. Ionasescu, J. A. Towbin, E. P. Bosch, S. L. Weinstein, S. W. Sernett, and K. P. Campbell. 1993. Duchenne muscular dystrophy: deficiency of dystrophin-associated proteins in the sarcolemma. Neurology. 43:795-800.

15. Matsumura, K., F. M. S. Tome, H. Collin, K. Azibi, M. Chaouch, J.-C. Kaplan, M. Fardeau, and K. P. Campbell. 1992. Deficiency of the $50 \mathrm{~K}$ dystrophin-associated glycoprotein in severe childhood autosomal recessive muscular dystrophy. Nature (Lond.). 359:320-322.

16. Matsumura, K., I. Nonaka, K. Arahata, and K. P. Campbell. 1993. Partial deficiency of dystrophin-associated proteins in a young girl with sporadic myopathy and normal karyotype. Neurology. 43:1267-1268.

17. Tinsley, J. M., D. J. Blake, A. Roche, U. Fairbrother, J. Riss, B. C. Byth, A. E. Knight, J. Kendrick-Jones, G. K. Suthers, D. R. Love, et al. 1992. Primary structure of dystrophin-related protein. Nature (Lond.). 360:591-593.

18. Lemaire, C., R. Heilig, and J. Mandel. 1988. The chicken dystrophin cDNA: striking conservation of the $C$-terminal coding and 3 ' untranslated regions between man and chicken. EMBO (Eur. Mol. Biol. Organ.) J. 7:4157-4162.

19. Koenig, M., A. H. Beggs, M. Moyer, S. Scherpf, K. Heindrichs, T. Bettecken, G. Meng, C. R. Muller, M. Lindlof, H. Kaariainen, et al. 1989. The molecular basis for Duchenne versus Becker muscular dystrophy: correlation of severity with type of deletion. Am. J. Hum. Genet. 45:498-506.

20. Cullen, M. J., J. Walsh, L. V. B. Nicholson, and J. B. Harris. 1990. Ultrastructural localization of dystrophin in human muscle by using gold immunolabelling. Proc. R. Soc. Lond. B Biol. Sci. 240:197-210.

21. Cullen, M. J., J. Walsh, L. V. B. Nicholson, J. B. Harris, E. E. ZubrzyckaGaarn, P. N. Ray, and R. G. Worton. 1991. Immunogold labeling of dystrophin in human muscle, using an antibody to the last 17 amino acids of the $\mathrm{C}$-terminus. Neuromuscular Disorders. 1:113-119.

22. Suzuki, A., M. Yoshida, H. Yamamoto, and E. Ozawa. 1992. Glycoprotein-binding site of dystrophin is confined to the cysteine-rich domain and the first half of the carboxyl-terminal domain. FEBS (Fed. Eur. Biochem. Soc.) Lett. 308:154-160.

23. Ohlendieck, K., J. M. Ervasti, K. Matsumura, S. D. Kahl, C. J. Leveille, and K. P. Campbell. 1991. Dystrophin-related protein is localized to neuromuscular junctions of adult skeletal muscle. Neuron. 7:499-508.

24. Matsumura, K., J. M. Ervasti, K. Ohlendieck, S. D. Kahl, and K. P. Campbell. 1992. Association of dystrophin-related protein and dystrophin-associated proteins in $\mathrm{mdx}$ mouse muscle. Nature (Lond.). 360:588-591.

25. Hoffman, E. P., C. A. Garcia, J. S. Chamberlain, C. Angelini, J. R. Lupski, and R. Fenwick. 1991. Is the carboxyl-terminus of dystrophin required for membrane association? A novel, severe case of Duchenne muscular dystrophy. Ann. Neurol. 30:605-610.

26. Récan, D., P. Chafey, F. Leturcq, J.-P. Hugnot, N. Vincent, F. Tomé, H. Collin, D. Simon, P. Czernichow, L. V. B. Nicholson, M. Fardeau, J.-C. Kaplan, and J. Chelly. 1992. Are cysteine-rich and $\mathrm{COOH}$-terminal domains of dystrophin critical for sarcolemmal localization? J. Clin. Invest. 89:712-716.

27. Helliwell, T. R., J. M. Ellis, R. C. Mountford, R. E. Appleton, and G. E. Morris. 1992. A truncated dystrophin lacking the C-terminal domains is localized at the muscle membrane. Am. J. Hum. Genet. 50:508-514.

28. Bies, R. D., C. T. Caskey, and R. Fenwick. 1992. An intact cysteine-rich domain is required for dystrophin function. J. Clin. Invest. 90:666-672.

29. Clemens, P. R., P. A. Ward, C. T. Caskey, D. E. Bulman, and R. G. Fenwick. 1992. Premature termination mutation causing Duchenne muscular dystrophy. Neurology. 42:1775-1782.

30. Matsumura, K., I. Nonaka, F. M. S. Tomé, K. Arahata, H. Collin, F. Leturcq, D. Récan, J. C. Kaplan, M. Fardeau, and K. P. Campbell. 1993. Mild deficiency of dystrophin-associated proteins in Becker muscular dystrophy patients having in-frame deletions in the rod domain of dystrophin. Am. J. Hum Genet. In press.

31. Beggs, A. H., E. P. Hoffman, J. R. Snyder, K. Arahata, L. Specht, F. Shapiro, C. Angelini, H. Sugita, and L. M. Kunkel. 1991. Exploring the molecular basis for variability among patients with Becker muscular dystrophy: dystrophin gene and protein studies. Am. J. Hum. Genet. 49:54-67.

32. Matsumura, K., and N. Imoto. 1991. Two long-living brothers of dystrophin-related muscular dystrophy with an in-frame deletion of exon 3 of the dystrophin gene: clinical features and diagnosis. Clin. Neurol. (Tokyo). 31:286-290. 